Original Research Article

\title{
Chemical Characterization Of Commercial Balsamic Vinegar Glaze
}

\author{
Lisa Lancellotti $^{\mathrm{a}}$, Alessandro Ulrici ${ }^{\mathrm{b}}$, Simona Sighinolfi ${ }^{\mathrm{a}}$, Andrea Marchetti ${ }^{\mathrm{a}, *}$ \\ ${ }^{\text {a }}$ Department of Chemical and Geological Sciences, University of Modena and Reggio Emilia, Via G. Campi 103, 41125 Modena, Italy \\ ${ }^{\mathrm{b}}$ Department of Life Sciences, University of Modena e Reggio Emilia, Via Amendola, 2, 42122 Reggio Emilia, Italy
}

\section{A R T I C L E I N F O}

\section{Keywords:}

balsamic vinegar reduction

balsamic vinegar glaze

phenolic acids

metal content

glucose

fructose

furfurals

\begin{abstract}
A B S T R A C T
The present study reports the chemical characterization of commercial balsamic vinegar glaze (BVG), a side product of the world-famous Aceto Balsamico di Modena (ABM). BVG, originally a homemade sweet and sour sauce, is now produced on an industrial scale and is gaining a growing success. The determination of total titratable acidity, dry matter, ash, metals, sugars, phenolic acids and furfurals is reported for BVG samples of different batches and years of production. Principal component analysis (PCA) and ANOVA test were applied to evaluate the experimental data. The results showed that the chemical characteristics of the product are almost unchanged in the investigated years and well reflect the characteristics of the ABM. Moreover, it was found that potentially harmful species, namely furfural compounds and heavy metals, were at a lower concentration than that of homologous products. In particular, the concentration of heavy metals, such as $\mathrm{Cu}, \mathrm{Zn}$ and $\mathrm{Pb}$, suggests that a preventive demetallization of the BVG starting raw materials occurs.
\end{abstract}

\section{INTRODUCTION}

Nowadays, consumers are increasingly demanding and selective, especially in the food field. Among the several factors that influence customer behavior, the attributes of a food product are relevant elements in the decision-making process. In addition to the organoleptic qualities, ingredients, health and safety features, a link with a specific territory contributes to adding value to the food product.

In this last context, since 1992 the European Union has protected high-quality agricultural products based on their geographical origin (Regulation (EU) No 1151, 2012). This protection is recognized through the introduction of quality marks, namely the protected designation of origin, PDO, the protected geographical origin, PGI, and the traditional specialties guarantee, TSG, aimed at avoiding fraud and damage to the consumers and producers as well. The promotion of food with specific characteristics, the improvement of the income of farmers with a better-quality vocation and the promotion of traditional processes through innovations are the foundations of the European approach to increase health, safety and overall quality of food products.

Therefore, to be competitive, the food industry mainly has to focus its efforts on the reliability of quality and safety rather than on quantity and price. Based on these considerations, the chemical characterization of products, following holistic approaches able to support the "from farm to fork/table" concept, constitutes an effective tool to provide objective information. In particular, the determination of different chemical parameters plays a key role for two distinct targets: the product characterization and the validation of the production process.

This study is intended to be a first step in the analysis of the balsamic vinegar glaze (BVG), also commercially known as balsamic vinegar reduction, sauce or cream. BVG is a side product of one of the most famous Italian condiments that represent food excellence in the world: the Balsamic Vinegar of Modena, Aceto Balsamico di Modena (ABM), a Protected Geographical Indication (PGI) awarded product (Regulation (EC) No 583, 2009).

BVG is a sweet-and-sour dressing and represents a traditional homecooked preparation obtained by boiling down, in a small pan, ABM with sugar or honey, flour and different flavors, such as garlic, truffle, basil, raspberry, etc., depending on personal taste, until a glaze is obtained. Basically, a balsamic vinegar reduction is a concentrated and thickened version of balsamic vinegar and many people choose the BVG as an alternative to the most expensive Aceto Balsamico Tradizionale di Modena (ABTM) (Cocchi et al., 2002) or in the absence of an aged ABM (Regulation (EC) No 583, 2009). The main drawback of the home-cooked preparation is the formation of potentially harmful compounds. In fact, when foods with high sugar content are subjected to thermal treatment a series of chemical modifications occur, such as the formation of furan compounds, principally furan and 5-hydroxymethyl furfural (HMF) (Kowalski et al., 2013). Since the toxic effects on

\footnotetext{
* Corresponding author at: Department of Chemical and Geological Sciences, Via Giuseppe Campi 103, 41125, Modena, Italy

E-mail address: andrea.marchetti@unimore.it (A. Marchetti).
} 
human health of furan and its derivatives are still controversial, the monitoring of these species is always recommended (Glatt, Sommer, 2006).

In the last decades, the ABM-based glaze has found great success and, to meet consumer preferences and expectations and market requirements, companies in the food sector are asked to develop new forms of convenient food. Currently, the food industry provides a wide range of differently flavored balsamic creams, that taste homemade but are ready-to-use and packed in an easy-to-squeeze bottle. The commercial BVG represent an economic product that combines practicality and connection to the territory, being a PGI-based product.

The industrial preparation is obtained by mixing, with the aid of special gear pumps, concentrated grape must, ABM (at least 20\%), modified cornstarch (about $3 \%$ ) and flavors. The presence of modified cornstarch allows the formation of a gel with high viscosity that gives the product its typical creamy consistency (Tharanathan, 2005). Due to its composition, BVG has chemical characteristics that are halfway between those of $\mathrm{ABM}$ and grape musts. Concerning the physical properties, such as viscosity and density, these are mainly regulated by the quantity and type of the modified cornstarch and the concentrated must added to the other ingredients (Saha \& Bhattacharya, 2010).

The advantage of the industrial production process, with respect to the homemade preparation, is that the formation of carbonized sugars is avoided or at least minimized, thus also the bitter taste that is usually present in the home-cooked preparation is absent. Moreover, industrial production also guarantees a controlled acidity that derives from the $\mathrm{ABM}$, which increases the BVG conservation and healthiness of the product.

Contrary to the provisions of the $\mathrm{ABM}$, whose production process is regulated by a specific production rule (Regulation (EC) No 583, 2009), that limits to a well-defined value some chemical/physical parameters (e.g. the density, total acidity and minimum amount of reducing sugars), to date the production of the marketable BVG is not subjected to similar rules. Furthermore, while ABM and ABTM have been extensively studied (Caligiani et al., 2007; Consonni et al., 2008; Lalou et al., 2015; Lemmetti \& Giudici, 2011), to date no studies have been reported in the literature about the chemical analysis of BVG. For these reasons, this study represents a first approach to the characterization of the marketable balsamic vinegar glaze, in terms of chemical composition and production monitoring.

Our attention was focused on the determination of the following analytical parameters: sugars, furfurals, phenolic acids, dry matter, ash, total titratable acidity and metals content, that typically represent the main components of the raw materials used in the BVG formulation. In particular, the aim of this first study on BVG chemical composition was to evaluate the effect of the variability of the raw materials on the chemical composition of the final product. To better focus on this aspect, we have limited our study to a single producer from the province of Modena (Italy), investigating the chemical composition of 24 marketable BVG samples, coming from different production batches, produced over three years. One-way ANOVA and Principal Component Analysis (PCA) were used to estimate the variability of the samples, focusing both on the single analytical parameters and on the chemical composition of the samples as a whole.

\section{MATERIALS AND METHODS}

\subsection{Chemicals}

High purity deionized water, type 1, was obtained from a Milli Q Element system (Millipore, Bedford MD, USA). Physical and chemical parameters for Type 1 water comply with ASTM and ISO 3696 grade purity specification (ASTM D1193, 1999).

All standards were obtained from Sigma Aldrich (Milan, Italy), with a purity greater than $99 \%$.

Phosphoric acid, trifluoracetic acid (TFA), with a purity greater than
99\%, diethyl ether, methanol (MeOH), acetonitrile (ACN), HPLC grade, and reagent grade $0.1 \mathrm{~N}$ sodium hydroxide standard solution were purchased from VWR International (Milan, Italy).

\subsection{Sample collection}

Twenty-four bottles of marketable unflavored BVG, coming from different batches, representative of the annual production of the years 2015, 2016 and 2017, were obtained directly from a local producer. Samples were properly stored in a cool and dry place, away from direct sunlight, according to producer indication reported on the bottle, to avoid any degradation. Each bottle of BVG was homogenized before taking a sub-sample to be analyzed.

\subsection{Analytical methodologies}

\subsubsection{Sugars}

The sugars, glucose and fructose, were determined by liquid chromatography technique (OIV, 2019). In particular, a HPLC apparatus, equipped with a Beckman 116 solvent pump, a Beckman 406 analog-digital interface, a Rheodyne 7025 injector with a $20 \mu \mathrm{L}$ fixed volume loop, a Shodex Sugar SH1011 column (300 mm x $8.0 \mathrm{~mm}$ i.d.) thermostated at $34.0 \pm 0.1{ }^{\circ} \mathrm{C}$ and a HP 1047 refractive index detector thermostated at $40.0 \pm 0.1{ }^{\circ} \mathrm{C}$, was used. The separation was performed, in isocratic elution mode, at $1.25 \mathrm{~mL} / \mathrm{min}$ with water as mobile phase. Samples were diluted about 1000 times by weight with deionized water and filtered, through a $0.22 \mu \mathrm{m}$ hydrophilic membrane, prior to the injection. Glucose and fructose were identified at 5.9 and $6.4 \mathrm{~min}$, respectively. Quantification was carried out by means of an external calibration curve accomplished for each measurement session. A randomly selected BVG sample was used as a control sample and measured several times over the different measurement sessions. The standard deviations calculated for glucose and fructose in this sample were then associated with all samples.

\subsubsection{Furfurals}

Furfurals were determined by HPLC equipped with a Gynkotek HP580Bio pump, a Rheodyne 7025 injector with a $20 \mu \mathrm{L}$ fixed volume loop, a Biorad column $(250 \times 4.6 \mathrm{~mm}, 5 \mu \mathrm{m}$ particle size $)$ C18 reversedphase, thermostated at $25 \pm 0.1{ }^{\circ} \mathrm{C}$, and a Gynkotek 340S UV-Vis diodearray detector (scan range set at $190-600 \mathrm{~nm}$ ). The separation was performed, in isocratic elution mode, at $0.9 \mathrm{~mL} / \mathrm{min}$ using a mixture of water-ACN (10:90), both containing $0.07 \%(\mathrm{v} / \mathrm{v})$ phosphoric acid, as mobile phase. The number of compounds belonging to the furfural family that are present in BVG is very large. Identification was carried out for 5-hydroxymethylfurfural (5-HMF), furfural, furfuryl alcohol and 2-furoic acid, while quantification was limited to 5-HMF and furfural, since the others were lower than the limit of quantification. In particular, furan derivatives detection was carried out at $285 \mathrm{~nm}$ (5-hydroxymethylfurfural, $t_{R}=6.9 \mathrm{~min}$ ), $277 \mathrm{~nm}$ (furfural, $t_{R}=13.1 \mathrm{~min}$ ), $252 \mathrm{~nm}$ (2-furoic acid, $t_{R}=11.6 \mathrm{~min}$ ) and $217 \mathrm{~nm}$ (furfuryl alcohol, $t_{R}=9.5 \mathrm{~min}$ ). Samples were diluted about 500 times by weight with deionized water and filtered, through a $0.22 \mu \mathrm{m}$ hydrophilic membrane, before injection. Quantification was carried out by means of an external calibration curve accomplished for each measurement session. A randomly selected sample was used as a control sample and measured several times over the different measurement sessions. The standard deviations calculated for the species determined in this sample were then associated with all samples.

\subsubsection{Phenolic acids}

Phenolic acids were determined by liquid chromatography with a HPLC equipped with a Gynkotek HP580Bio pump, a Rheodyne 7025 injector with a $100 \mu \mathrm{L}$ fixed volume loop, an Atlantis C18 column ( $250 \times$ $4.6 \mathrm{~mm}, 5 \mu \mathrm{m}$ particle size) and C18 guard column, thermostated at $25 \pm$ $0.1{ }^{\circ} \mathrm{C}$, and a Gynkotek $340 \mathrm{~S}$ UV-vis diode-array detector (scan range set 
at $190-600 \mathrm{~nm})$. The separation was performed with linear gradient elution using a binary solvent system of $0.1 \%(\mathrm{v} / \mathrm{v})$ TFA in water $(\mathrm{A})$ and $0.1 \%(\mathrm{v} / \mathrm{v})$ TFA in ACN (B) and detection at $280 \mathrm{~nm}$ (Salvatore et al., 2013). Instrumental separation conditions are reported, as supplementary material, in Table 1S. The chromatographic determination of phenolic acids was carried out after analyte extraction by means of solid-phase extraction (SPE).

Extraction of phenolic acids was carried out using Discovery DPA-6S cartridges (500 mg, polymeric reversed-phase, Supelco, Milan, Italy). The cartridge was first activated with $4 \mathrm{~mL}$ of $\mathrm{MeOH}$ followed by $2 \mathrm{~mL}$ of deionized water, then $1 \mathrm{~mL}$ of 10 times diluted sample was loaded. The cartridge was then washed with $2 \mathrm{~mL}$ of water and the unbounded eluted fraction discarded. Elution of phenolic acids was achieved by washing the cartridge with $4 \mathrm{~mL}$ of $\mathrm{MeOH}$ followed by $6 \mathrm{~mL}$ of diethyl ether.

The phenolic acid fraction was then evaporated to dryness, under $\mathrm{N}_{2}$ stream, and re-dissolved with $1 \mathrm{~mL}$ of water-MeOH (80:20). Samples were filtered through a $0.22 \mu \mathrm{m}$ syringe filter prior to the HPLC injection.

Quantification of the phenolic species was carried out for the following compounds: gallic acid $\left(t_{R}=15.8 \mathrm{~min}\right)$, protocatechuic acid $\left(t_{R}=20.3 \mathrm{~min}\right)$, caffeic acid $\left(t_{R}=27.0 \mathrm{~min}\right)$, syringic acid $\left(t_{R}=27.2\right.$ $\mathrm{min})$, and $p$-coumaric acid $\left(\mathrm{t}_{\mathrm{R}}=31.9 \mathrm{~min}\right)$. Caffeic and syringic acids were quantified together as syringic acid equivalent, due to a partial overlap of the respective chromatographic signals. Samples were analyzed in duplicate and quantified by means of an external calibration curve accomplished for each measurement session.

Fig. 1 shows an example of the HPLC separation carried out on a mixture of standard phenolic compounds, plot A, and on a BVG sample, plot B.
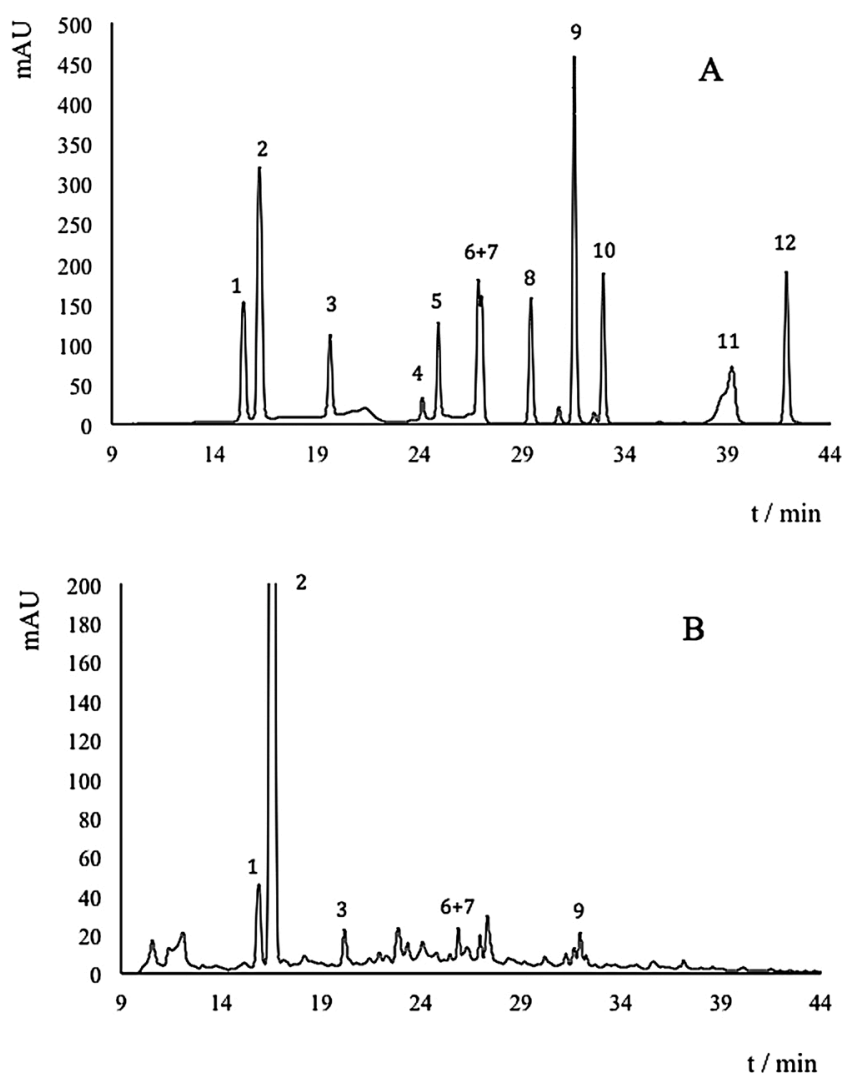

Fig. 1. A, Chromatographic separation of a phenolic acid standard mixture. 1. Gallic acid; 2. 5-HMF; 3. Protocatechuic acid; 4. (+)-Catechin; 5. Chlorogenic acid; 6. Caffeic acid; 7. Syringic acid; 8. Vanillin; 9. p-Coumaric acid; 10. Ferulic acid; 11. Myricetin; 12. 4-Dimethylaminocinnamaldehyde. B, chromatographic separation of a real BVG sample.

\subsubsection{Dry matter and ash measurement}

Aliquots of about $4 \mathrm{~g}$ of sample were weighed into quartz crucible and subjected to heat treatment for seven days in an ISCO oven (Milan, Italy) set at $104 \pm 2{ }^{\circ} \mathrm{C}$. Dried samples were then weighted to determine dry matter content. Ash measurement was carried out by means of a Nannetti Kiln HB muffle furnace (Faenza, Italy) set at $600 \pm 25^{\circ} \mathrm{C}$. The dried samples, coming from dry matter determination, were subjected to high-temperature treatment for $24 \mathrm{~h}$. All sample measurements were repeated twice.

\subsubsection{Total titratable acidity}

Total titratable acidity (TA) was determined by $\mathrm{pH}$ metric titration with a Denver Instrument, $215 \mathrm{pH}$-meter equipped with a combined Schott glass electrode (OIV, 2019). For TA determination, $1 \mathrm{~g}$ of sample was weighed and titrated with $0.1 \mathrm{~N} \mathrm{NaOH}$. The titration endpoint was mathematically determined by means of first and second derivative techniques. All the samples were measured in triplicate.

\subsubsection{Metals}

Metal content was determined by means of atomic absorption spectroscopy (AAS) (OIV, 2019). In particular, Li, Na, K, Mg, Ca, Fe, Cu and $\mathrm{Zn}$, were determined by means of a FS220 flame atomic absorption spectrometer (FAAS), equipped with a SIPS10 sample introduction pump system, both supplied by Agilent (Milan, Italy). While, $\mathrm{Pb}$ and $\mathrm{Mn}$, were determined by means of a Perkin Elmer SIMAA6000 graphite furnace spectrometer (GFAAS), equipped with a dedicated Zeeman background correction system (Milan, Italy). FAAS and GFAAS instrument parameters are reported, as supplementary material, in Table $2 S$ and $3 S$, respectively. All the samples were measured twice.

\subsubsection{Limits of detection and quantification}

Both the detection limit (LOD) and quantification limit (LOQ) were determined based on the method described by Miller \& Miller (2010). In particular, the LOD was determined as the analyte concentration giving a signal equal to the blank signal, $\mathrm{y}_{\mathrm{B}}$, plus three standard deviations of the blank, $\mathrm{S}_{\mathrm{B}}$; while LOQ was calculated using the formula: $\mathrm{y}_{\mathrm{B}}+10 \mathrm{~S}_{\mathrm{B}}$. In Table 4S, reported as supplemental material, are reported LOD and LOQ values in addition to the working calibration ranges.

\subsection{Data analysis}

One-way analysis of variance (ANOVA) and the Tukey multiple comparison test were used to check for significant differences $(\mathrm{P}=95 \%)$ among the three years of production. Moreover, in order to obtain a general overview of the collected data, by exploring the contribution of all the considered parameters to the variability of the analyzed samples, principal component analysis (PCA) was applied.

Since variables had different scales and units, PCA was calculated on autoscaled variables. Autoscaling consists in transforming each variable by subtracting its average value and then dividing it by its standard deviation. This transformation allows the data to be translated at the origin of the reference system since each variable will have an average value equal to zero, and also makes the variability of each variable equally important in the construction of the PCA model, since each variable will have a standard deviation equal to one (Wise and Gallagher, 1996). One-way ANOVA and Tukey multiple comparison test were performed using the Statistics and Machine Learning Toolbox (ver. 11.2, The MathWorks Inc., Natick, MA, USA), while the PCA model was calculated using the PLS Toolbox (ver. 8.6, Eigenvector Research Inc., Wenatchee, WA, USA); both the Toolboxes run in the Matlab environment (ver. 9.3, The MathWorks Inc., Natick, MA, USA).

\section{Results and discussion}

All the experimental results for individual samples are reported, as supplementary material, from Tables $5 \mathrm{~S}$ to $9 \mathrm{~S}$. 
Table 1 reports the average values of the analytes measured in the balsamic vinegar glazes, for the three years of production, together with the one-way ANOVA and the Tukey multiple comparison test results.

\subsection{Sugars}

Sugars, namely glucose and fructose, represent the main components of the glaze. The presence of the two monosaccharides is due to both the concentrated grape must, that typically contains about $700 \mathrm{~g} / \mathrm{kg}$ of sugars, and the $\mathrm{ABM}$, where reducing sugars concentration must not be less than $110 \mathrm{~g} / \mathrm{L}$ (Regulation (EC) No 583, 2009).

The average concentration of glucose and fructose over the three considered years was approximately 220 and $227 \mathrm{~g} / \mathrm{kg}$, respectively, and their ratio (glu/fru) was approximately equal to 0.97 .

Concerning the statistical evaluation of the data, one-way ANOVA showed a statistically significant difference among the years for both glucose and fructose. The Tukey multiple comparison tests highlighted a decreasing trend with increasing years for both the sugars, with significant differences between 2015 and 2017 (Table 1). As for the samples from 2016, while glucose showed intermediate values with no statistical differences with respect to 2015 and 2017, the mean value of fructose was comparable to 2015 and different from 2017. Considering that the sugar variation involves both glucose and fructose, a plausible explanation for this evidence might be a variation of the starting raw material used to produce grape must and ABM.

The glucose/fructose ratio did not show statistically significant variations over the three years, and it perfectly reflects the value that is commonly found in oenological products (Cocchi et al., 2006).

\subsection{Furfurals}

When food containing reducing sugars is subjected to heat treatment under acid conditions, Maillard reactions occur and the formation of different furan derivatives is observed (Kowalski et al., 2013). Moreover, 5-hydroxymethylfurfural and furfural are present in food products that have been in contact with wood for long periods, for example in aged vinegar (Cocchi et al., 2011). As a consequence, the presence of these species in BVG is not surprising and can be attributed to both the ABM and the concentrated grape must.

As expected, despite showing a high variability, the furfural concentration in BVG was relatively low in comparison with homologous products, such as PGI ABM and PDO traditional balsamic vinegar of Modena (ABTM), for which 5-HMF values often exceed $5000 \mathrm{mg} / \mathrm{kg}$ (Manzini et al., 2011; Masino et al., 2008). In any case, the low acidity of the product, about $2 \% \mathrm{w} / \mathrm{w}$, helps to maintain the 5 -HMF values as low as possible. Even if no statistically significant differences were highlighted among the three years of production, a general decreasing trend of the average values was observed from 2015 to 2017 (Table 1). This could be ascribed to the fact that the improvement of the technological processes for the production of musts: namely, the use of multiple effects evaporating towers operating at low temperature and high vacuum processing conditions, was such as to reduce the formation of these species.

\subsection{Phenolic acids}

In addition to the well-recognized protective role of phenolic acids on human health (Kumari, 2012), the investigation of these species is also related to the sensory quality of food. In fact, these compounds play an important role in several sensory properties, such as color, flavor, astringency and hardness, of food products like wine and wine vinegar.

Phenolic acids composition is affected by grape quality and oenological practices (Cerezo et al., 2008, 2010; Van Leeuw et al., 2014). The presence of phenolic acids in wine and vinegar is mainly due to their natural content in grapes, as secondary metabolites of plants, and content is increased if the grape-derived products are kept in contact with wood during the ageing period. A typical example of a phenolic acid that is strongly dependent on wood type is gallic acid (Cerezo et al., 2010).

Gallic acid was the most abundant phenolic compound identified, followed by protocatechuic acid, caffeic and syringic acids and finally $p$ coumaric acid. The concentration of the phenolic acids, determined in BVG, agrees well with that reported for wine vinegar and balsamic vinegar (Cerezo et al., 2008, 2010). From a statistical point of view, one-way ANOVA did not show statistically significant differences of the investigated species over the three years, with the only exception of gallic acid, for which the average concentration of samples of 2015 was significantly lower than the average value of 2016, while 2017 samples showed an intermediate value (Table 1).

Table 1

mean values and associated standard deviation values of the analytes determined in the balsamic vinegar glazes for the three investigated years of production, together with the one-way ANOVA results $\left(\mathrm{df}_{\text {between }}=2\right.$; $\mathrm{df}_{\text {within }}=21$ ). Different superscript letters indicate statistical differences between different years (Tukey multiple comparison test, $\mathrm{P}=95 \%)$.

\begin{tabular}{|c|c|c|c|c|c|c|c|c|c|c|c|c|}
\hline Parameter & Units & 2015 & & & 2016 & & & 2017 & & & $\mathrm{~F}$ & p-value* \\
\hline Glucose & $\mathrm{g} / \mathrm{kg}$ & $226^{\mathrm{a}}$ & \pm & 8 & $223^{\mathrm{a}, \mathrm{b}}$ & \pm & 14 & $211^{\mathrm{b}}$ & \pm & 8 & 4.793 & 0.0193 \\
\hline Fructose & $\mathrm{g} / \mathrm{kg}$ & $235^{\mathrm{a}}$ & \pm & 10 & $229^{a}$ & \pm & 6 & $216^{\mathrm{b}}$ & \pm & 7 & 12.121 & 0.0003 \\
\hline Glu/Fru ratio & - & $0.96^{\mathrm{a}}$ & \pm & 0.03 & $0.97^{\mathrm{a}}$ & \pm & 0.06 & $0.98^{\mathrm{a}}$ & \pm & 0.02 & 0.507 & 0.6087 \\
\hline 5-HMF & $\mathrm{mg} / \mathrm{kg}$ & $956^{\mathrm{a}}$ & \pm & 473 & $824^{\mathrm{a}}$ & \pm & 591 & $521^{\mathrm{a}}$ & \pm & 376 & 1.575 & 0.2305 \\
\hline Furfural & $\mathrm{mg} / \mathrm{kg}$ & $14^{\mathrm{a}}$ & \pm & 12 & $10^{\mathrm{a}}$ & \pm & 6 & $7^{\mathrm{a}}$ & \pm & 5 & 1.494 & 0.2475 \\
\hline Gallic acid & $\mathrm{mg} / \mathrm{kg}$ & $18^{\mathrm{a}}$ & \pm & 6 & $29^{\mathrm{b}}$ & \pm & 13 & $23^{\mathrm{a}, \mathrm{b}}$ & \pm & 5 & 3.532 & 0.0476 \\
\hline Protocatechuic acid & $\mathrm{mg} / \mathrm{kg}$ & $12^{\mathrm{a}}$ & \pm & 5 & $13^{\mathrm{a}}$ & \pm & 4 & $17^{\mathrm{a}}$ & \pm & 6 & 1.743 & 0.1994 \\
\hline Syringic-Caffeic acids & $\mathrm{mg} / \mathrm{kg}$ & $4.3^{\mathrm{a}}$ & \pm & 2.3 & $7^{\mathrm{a}}$ & \pm & 2.9 & $6^{\mathrm{a}}$ & \pm & 1.8 & 2.822 & 0.0821 \\
\hline p-Coumaric acid & $\mathrm{mg} / \mathrm{kg}$ & $1.8^{\mathrm{a}}$ & \pm & 0.7 & $1.3^{\mathrm{a}}$ & \pm & 0.6 & $1.2^{\mathrm{a}}$ & \pm & 0.4 & 2.424 & 0.1129 \\
\hline Dry matter & $\mathrm{g} / \mathrm{kg}$ & $594^{\mathrm{a}, \mathrm{b}}$ & \pm & 14 & $601^{\mathrm{a}}$ & \pm & 21 & $576^{\mathrm{b}}$ & \pm & 8 & 5.556 & 0.0116 \\
\hline Ash & $\mathrm{g} / \mathrm{kg}$ & $8.2^{\mathrm{a}}$ & \pm & 0.6 & $8.2^{\mathrm{a}}$ & \pm & 1.1 & $9.5^{\mathrm{a}}$ & \pm & 2 & 2.427 & 0.1127 \\
\hline Total Acidity & $\%$ & $2.1^{\mathrm{a}}$ & \pm & 0.1 & $2.1^{\mathrm{a}}$ & \pm & 0.1 & $2.2^{\mathrm{a}}$ & \pm & 0.2 & 2.422 & 0.1131 \\
\hline $\mathrm{Li}$ & $\mathrm{mg} / \mathrm{kg}$ & $0.22^{\mathrm{a}, \mathrm{b}}$ & \pm & 0.03 & $0.25^{\mathrm{a}}$ & \pm & 0.01 & $0.21^{\mathrm{b}}$ & \pm & 0.02 & 7.565 & 0.0034 \\
\hline $\mathrm{Na}$ & $\mathrm{mg} / \mathrm{kg}$ & $448^{\mathrm{a}}$ & \pm & 30 & $423^{\mathrm{a}}$ & \pm & 94 & $451^{\mathrm{a}}$ & \pm & 93 & 0.306 & 0.7394 \\
\hline $\mathrm{K}$ & $\mathrm{mg} / \mathrm{kg}$ & $2872^{\mathrm{a}}$ & \pm & 265 & $2959^{\mathrm{a}}$ & \pm & 450 & $3199^{a}$ & \pm & 723 & 0.897 & 0.4229 \\
\hline $\mathrm{Mg}$ & $\mathrm{mg} / \mathrm{kg}$ & $276^{\mathrm{a}}$ & \pm & 47 & $248^{\mathrm{a}, \mathrm{b}}$ & \pm & 43 & $213^{\mathrm{b}}$ & \pm & 39 & 4.111 & 0.0312 \\
\hline $\mathrm{Ca}$ & $\mathrm{mg} / \mathrm{kg}$ & $339^{\mathrm{a}, \mathrm{b}}$ & \pm & 37 & $393^{\mathrm{a}}$ & \pm & 68 & $310^{\mathrm{b}}$ & \pm & 43 & 5.248 & 0.0142 \\
\hline Mn & $\mu \mathrm{g} / \mathrm{kg}$ & $1484^{\mathrm{a}}$ & \pm & 496 & $1857^{\mathrm{a}}$ & \pm & 536 & $1496^{\mathrm{a}}$ & \pm & 187 & 1.808 & 0.1886 \\
\hline $\mathrm{Fe}$ & $\mathrm{mg} / \mathrm{kg}$ & $7.9^{\mathrm{a}}$ & \pm & 3.3 & $6.9^{\mathrm{a}}$ & \pm & 2 & $8.9^{\mathrm{a}}$ & \pm & 2.3 & 1.069 & 0.3614 \\
\hline $\mathrm{Cu}$ & $\mathrm{mg} / \mathrm{kg}$ & $0.47^{\mathrm{a}}$ & \pm & 0.3 & $0.83^{\mathrm{a}, \mathrm{b}}$ & \pm & 0.34 & $1.01^{\mathrm{b}}$ & \pm & 0.56 & 3.596 & 0.0454 \\
\hline $\mathrm{Zn}$ & $\mathrm{mg} / \mathrm{kg}$ & $1.5^{\mathrm{a}}$ & \pm & 0.9 & $1.7^{\mathrm{a}}$ & \pm & 0.8 & $1.2^{\mathrm{a}}$ & \pm & 0.4 & 0.876 & 0.4313 \\
\hline $\mathrm{Pb}$ & $\mu \mathrm{g} / \mathrm{kg}$ & $64^{a}$ & \pm & 17 & $67^{\mathrm{a}}$ & \pm & 28 & $52^{\mathrm{a}}$ & \pm & 10 & 1.222 & 0.3146 \\
\hline
\end{tabular}

"statistically significant differences (p-value $<0.05)$ are highlighted in bold. 


\subsection{Dry matter}

Dry matter refers to the material that remains after water removal. As regards the BVG samples, dry matter is mainly composed of grape sugars, starch polysaccharides and non-volatile organic acids, in addition to minor components, such as inorganic salts and organic compounds at very low concentration that does not affect the measurement result. The average value of dry matter content, measured on the BVG samples, was, on the whole, about $60 \%$ and results agree with those found for similar products like traditional balsamic vinegars (Masino et al., 2008). One-way ANOVA and Tukey test highlighted a statistically significant difference between 2016 and 2017, while the samples collected during 2015 showed intermediate values (Table 1). In particular, samples produced during 2017 showed a lower dry matter content than those produced during 2016. This behavior well reflects the sugars trend and the highlighted difference is probably due to different composition of the starting raw materials, although changes in the production process are also possible.

\subsection{Ash content}

Chemical composition of ashes from BVG is due to thermostable compounds, namely metal oxides, phosphates, sulphates, etc. No statistically significant differences were observed among the three years (Table 1), even if a slightly higher value was observed for 2017 with respect to 2015 and 2016. Even in this case, data results in agreement with those observed for traditional balsamic vinegars (Masino et al., 2008).

\subsection{Total titratable acidity}

TA represents the sum of the fixed and volatile acids present in a sample. The TA of the product under investigation is mainly regulated by the amount of ABM used in the formulation since the contribution of the acidity from the concentrated must (fixed acidity) is quite low.

As far as vinegars or similar products are concerned, TA is expressed as the percentage of grams of acetic acid per $100 \mathrm{~g}$ of product. This parameter were almost constant for all the investigated samples, with annual mean values equal to $2.1 \pm 0.1 \%, 2.1 \pm 0.1 \%$ and $2.2 \pm 0.2 \%$ for 2015, 2016 and 2017, respectively.

Concerning the TA value of the BVG samples, it is not surprising to find such a low acidity value, about $2 \%$, when compared to the minimum acidity value, $6 \%$, required for a PGI ABM. In fact, since BVG is obtained by mixing ABM with concentrated grape must, whose acidity is very low, the resulting acidity of the product is expected to be much less than $6 \%$.

In addition, while the production of ABM is regulated by a specific production rule that sets a series of physicochemical parameters that must be strictly complied with, at present, BVG production is not, and the value of the total acidity has only a technical relevance for the stability of the gel conditions of the product. In fact, it is reasonable to hypothesize that high values of acidity may induce modifications of the starch structure, leading to a possible separation of phases and a consequent loss of the product rheological characteristics, making it unmarketable.

\subsection{Metals}

To date, the commercial balsamic reduction is not subjected to any type of restriction as regards the content of metals. Nevertheless, to evaluate the results obtained in the present study, the metal concentration limits, fixed for wines and musts (OIV, 2017) and the literature data concerning homologous products such as ABTM (Corradini et al., 1996, Cocchi et al., 2004), were taken into consideration.

Concerning $\mathrm{Li}$, the natural content of this metal in wines is very low (Catarino et al., 2006; Gomez et al., 2004); therefore, its determination is performed for a quality test rather than for nutritional purposes. The concentration of Li, measured in the analyzed samples, was less than 0.3 $\mathrm{mg} / \mathrm{kg}$. One-way ANOVA followed by Tukey test showed a significant difference among samples produced during 2016 and 2017, while 2015 samples showed intermediate values (Table 1 ).

As far as $\mathrm{Na}$ and $\mathrm{K}$ are concerned, the measured concentrations were quite homogeneous, over the investigated period, also confirmed by one-way ANOVA. Overall, Na ranged from 250 to $600 \mathrm{mg} / \mathrm{kg}$, while K, the most abundant cation among those measured, ranged from 2000 to $4400 \mathrm{mg} / \mathrm{kg}$. Considering that the main ingredient of BVG is concentrated grape must, the measured values were similar to those determined in ABTM (Corradini et al., 1996).

$\mathrm{Ca}$ and $\mathrm{Mg}$ represent quality parameters for oenological products. Generally, $\mathrm{Mg} / \mathrm{Ca}$ concentration ratio in grape musts and wines is about 1 , even if slightly positive or negative deviations are accepted. This trend is also confirmed for the samples under study, where the concentration range, for $\mathrm{Ca}$ and $\mathrm{Mg}$, was $250-600 \mathrm{mg} / \mathrm{kg}$ and $150-350 \mathrm{mg} / \mathrm{kg}$, respectively. One-way ANOVA and Tukey test highlighted significant differences for both the cations in the three years due to a decrease in their content in 2017 compared to the previous years (Table 1).

Concerning heavy metals, $\mathrm{Mn}, \mathrm{Fe}, \mathrm{Cu}, \mathrm{Zn}$ and $\mathrm{Pb}$ were determined. The presence of manganese, in oenological products, is directly linked to the capacity of the vine to absorb this element from the soil; consequently, its concentration can be extremely variable depending on the type of the vineyard soil (Slunjski et al., 2012; OIV, 2018). Mn concentration, determined in the BVG samples, ranged from 0.5 to 2.6 $\mathrm{mg} / \mathrm{kg}$. These values are, on average, lower when compared with those determined on similar food products (Cocchi et al., 2004).

Iron levels are generally related to machinery used in the production process such as pressing equipment, which is usually made of iron or stainless steel. The overall content were in the $4-14 \mathrm{mg} / \mathrm{kg}$ range. The experimental values did not show statistically significant differences in the different years, for both the cations; moreover, as regards the iron content, the measured values were found to be well below that measured in homologous products, such as ABTM.

Unlike the previous metals, in wines and musts, the presence of heavy metals such as copper, zinc and lead are subjected to legal limits. In particular, maximum allowed values are 1,5 and $0.15 \mathrm{mg} / \mathrm{kg}$ for $\mathrm{Cu}$, $\mathrm{Zn}$ and $\mathrm{Pb}$, respectively.

Copper, in the grape juice, originates from soil absorption as for most metals, but the main source is certainly given by copper-based agrochemical products. The $\mathrm{Cu}$ concentration, measured in the BVG samples, ranged from 0.2 to $1.8 \mathrm{mg} / \mathrm{kg}$, and for 6 samples out of 24 , Cu content exceeded the fixed limit. Moreover, ANOVA and Tukey test showed significant differences among the years, with $\mathrm{Cu}$ levels increasing from 2015 to 2017.

Concerning zinc, a quite high within-year variability was observed, and no statistically significant difference was highlighted over the years. Sample concentration ranged between 0.4 and $3.4 \mathrm{mg} / \mathrm{kg}$, lower than the fixed limit, for wine and musts, and the concentration values found in ABTM (Cocchi et al., 2004).

As for $\mathrm{Zn}$, the main source of lead, in oenological products, is environmental pollution (Angelova et al., 1999). Due to a toxicological hazard, the maximum acceptable limit of $\mathrm{Pb}$ is extremely low. None of the analyzed samples showed $\mathrm{Pb}$ content above the legal limit, with concentration values ranging from 0.04 to $0.12 \mathrm{mg} / \mathrm{kg}$, and no statistically significant differences were observed over the three years.

In summary, the concentration of the heavy metals measured in the BVG samples was lower than that of homologous products such as ABTM. This evidence strongly suggests that the starting raw materials of BVG were previously subjected to processes for the reduction of the metal content through demetallization practices.

\subsection{Exploratory data analysis}

Principal Component Analysis was applied to the whole dataset, with 
size $\{24 \times 22\}$, including the values of the 22 physicochemical parameters listed in Table 1 for the 24 BVG samples considered in this work, ordered according to the date of production. Based on the scree plot, two principal components (PCs) were selected, accounting for $40.11 \%$ of total data variance. No outliers were detected based on the inspection of the $\mathrm{Q}$ residuals $v$. Hotelling $\mathrm{T}^{2}$ plot (Fig. 2), suggesting that overall the composition of the analyzed batches is quite constant.

The PC1-PC2 score plot (Fig. 3) highlights that the samples of 2015 and 2016 are quite overlapped with each other and that samples of 2015 are separated in two clusters. In particular, the cluster including samples n. 4, 5 and 6, corresponding to the batches produced in mid-2015, lies at high positive values of PC2, due to the relatively high values of glucose, fructose and dry matter (Fig. 4).

A clear difference was instead observed between the BVG samples produced in 2017 and those of the previous two years. Except for sample n. 18, which corresponds to the first analyzed batch of 2017, the remaining 2017 samples are found on the lower part of the PC1-PC2 graph, together with sample 17, which corresponds to the last analyzed batch of 2016. These samples show tendentially high values of total acidity, $\mathrm{Na}, \mathrm{Fe}$ and $\mathrm{Cu}$, and low values of fructose, glucose, dry matter, Li, Mg and Ca (Fig. 4). This trend is coherent with the results of one-way ANOVA and Tukey multiple comparison test, except for total acidity, $\mathrm{Na}$ and $\mathrm{Fe}$, which did not show statistically significant differences among the three years, mainly due to sample 18 . The difference between the samples produced in 2017 and those of 2015 and 2016, is probably due to the fact that the formulation of BVG was changed to meet, on the one hand, a higher technological stability of the product and, on the other hand, consumers' preferences.

\section{CONCLUSIONS}

Balsamic vinegar glaze is a product obtained by mixing concentrated grape must and ABM, and addition of a small amount of cornstarch in order to obtain a creamy consistency. Often consumers choose BVG as an alternative to the most expensive ABTM, whose production is regulated by a precise and specific production rule (Gazzetta Ufficiale, 1987), as for ABM. Contrary, to date, BVG is not subjected to any regulation that limit, for example, the quantity or the type of the raw material used in the formulation of BVG. Moreover, to the best of our knowledge, to date, scientific literature reports no studies about BVG.

As a consequence, the present investigation is a preliminary study of the chemical characterization, in terms of main components and bulk parameters, of the BVG. Investigated variables helped improving knowledge about product characteristics, in terms of composition. The present research may constitute a starting point to develop monitoring

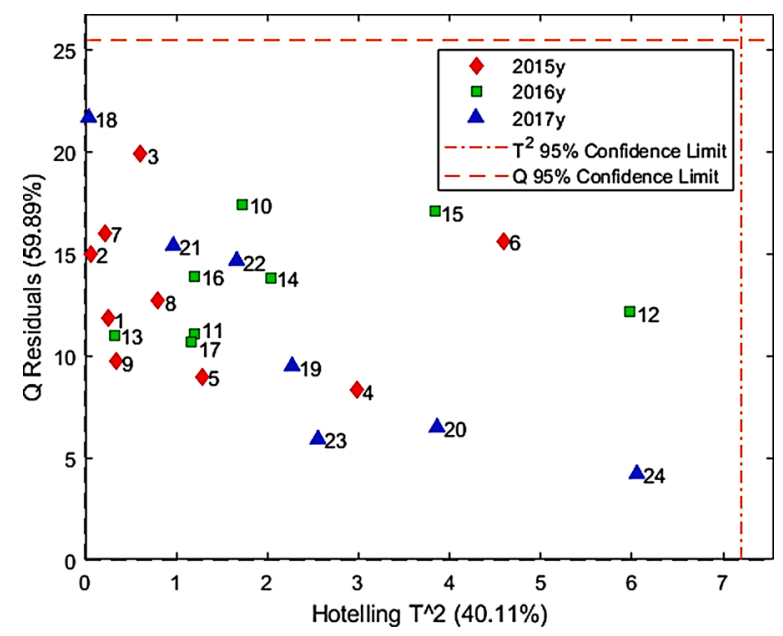

Fig. 2. Plot of the Hotelling $\mathrm{T}^{2}$ values vs. $\mathrm{Q}$ residuals for the calculated PCA model.

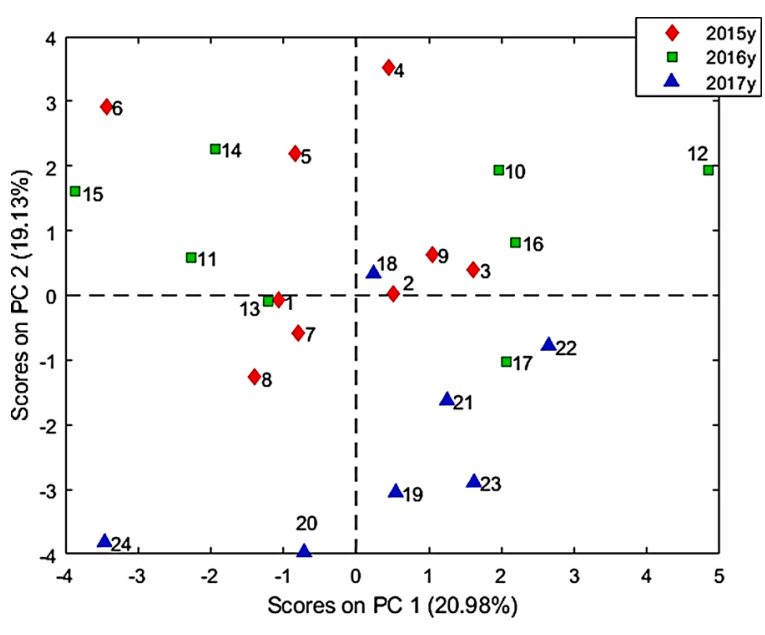

Fig. 3. PC1 vs. PC2 scores plot.

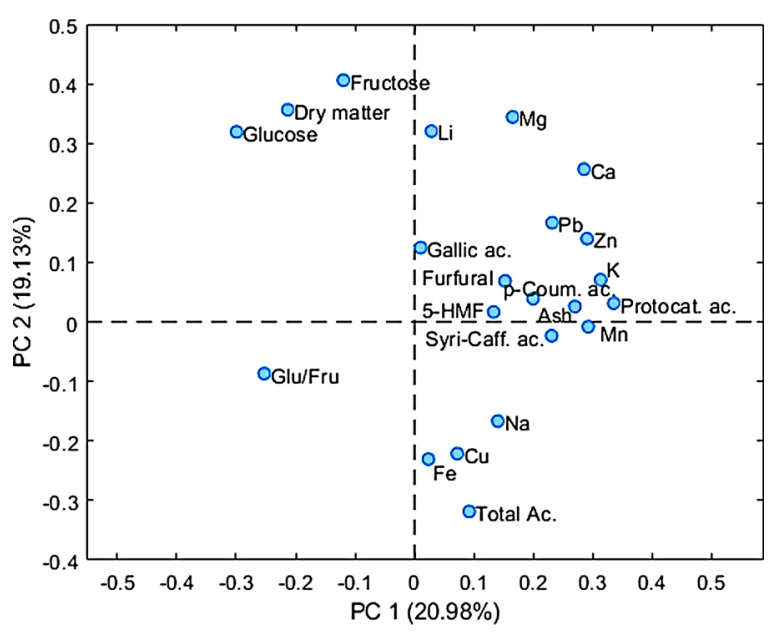

Fig. 4. PC1 vs. PC2 loadings plot.

procedures for process-control purposes and hazards control, based on objective variables typical of the product and, indirectly, of some of its main raw materials.

To this end, 24 samples of BVG, representative of three years of production were sampled from a local producer. Results obtained from the analysis of the samples of cream showed that the production process is well controlled as chemical parameters were mainly unchanged during the investigated period. During the considered production years, the balsamic glaze composition slightly changed towards to higher acidity values and lower sugar content.

The marketable product preserves the chemical characteristics of the starting raw materials such as ABM, although showing significant variations of some parameters such as glucose, fructose and total titratable acidity.

Concerning metals determination, the low content of heavy metals, detected in the samples, probably implies a preventive demetallization of the starting raw materials, despite some exceptions being observed. As for the content of metals, i.e. $\mathrm{Cu}, \mathrm{Zn}$ and $\mathrm{Pb}$, for which there is a legal limit for wine and grape musts, the analyzed BVG samples showed modest values, which guarantee the law requirements.

It should be taken into due consideration, however, that the formulation of BVG consists of a mixture of raw materials coming from supply chains with different product characteristics. Therefore, the final content of the chemical species is the result of a diversified and weighted contribution of products with an intrinsic variability. Starting from these results, further research work will be focused on an extensive 
characterization of BVG samples coming from different producers of the same geographic area.

\section{Declaration of Competing Interest}

The authors declare that they have no known competing financial interests or personal relationships that could have appeared to influence the work reported in this paper.

\section{Funding}

This research did not receive any specific grant from funding agencies in the public, commercial, or not-for-profit sectors.

\section{CRediT authorship contribution statement}

Lisa Lancellotti: Investigation. Alessandro Ulrici: Formal analysis, Writing - review \& editing. Simona Sighinolfi: Methodology, Formal analysis, Writing - original draft. Andrea Marchetti: Conceptualization, Project administration, Writing - review \& editing.

\section{Appendix A. Supplementary data}

Supplementary material related to this article can be found, in the online version, at doi:https://doi.org/10.1016/j.jfca.2020.103620.

\section{References}

Angelova, V., Ivanov, A., Braikov, D., Ivanov, K., 1999. Heavy metal (Pb, Cu, Zn and Cd) content in wine produced from grape cultivar Mavrud, grown in an industrially polluted region. Journal International des Sciences de la Vigne et du Vin 33, 119-131.

ASTM D1193, 1999. Standard Specification for Reagent Water, D19 Committee, standard $\mathrm{N}^{0}$ 7916. ASTM International, West Conshohocken, PA, USA.

Caligiani, A., Acquotti, D., Palla, G., Bocchi, V., 2007. Identification and quantification of the main organic components of vinegars by high resolution 1H NMR spectroscopy. Analytical Chimica Acta 585, 110-119.

Catarino, S., Capelo, J.L., Curvelo-Garcia, A.S., Bruno de Sousa, R., 2006. Evaluation of contaminant elements in Portuguese wines and original musts by high intensity focused ultrasound combined with inductively coupled plasma mass spectroscopy. Journal International des Sciences de la Vigne et du Vin 40, 91-101.

Cerezo, A.B., Tesfaye, W., Torija, M.J., Mateo, E., Garcia-Parilla, M.C., Troncoso, A.M., 2008. The phenolic composition of red wine vinegar produced in barrels made from different woods. Food Chemistry 109, 606-615.

Cerezo, A.B., Tesfaye, W., Soria-Diaz, M.E., Torija, M.J., Mateo, E., Garcia-Parilla, M.C., Troncoso, A.M., 2010. Effect of wood on the phenolic profile and sensory properties of wine vinegars during ageing. Journal of Food Composition and Analysis 23 , 175-184.

Cocchi, M., Lambertini, P., Manzini, D., Marchetti, A., Ulrici, A., 2002. Determination of carboxylic acids in vinegars and in Aceto Balsamico Tradizionale di Modena by HPLC and GC methods. Journal of Agricultural and Food Chemistry 50, 5255-5261.

Cocchi, M., Franchini, G., Manzini, D., Manfredini, M., Marchetti, A., Ulrici, A., 2004. A chemometric approach to the comparison of different sample treatments for metals determination by atomic absorption spectroscopy in Aceto Balsamico Tradizionale di Modena. Journal of Agricultural and Food Chemistry 52, 4047-4056.

Cocchi, M., Durante, C., Grandi, M., Lambertini, P., Manzini, D., Marchetti, A., 2006. Simultaneous determination of sugars and organic acids in aged vinegars and chemometric data analysis. Talanta 69, 1166-1175.

Cocchi, M., Durante, C., Lambertini, P., Manzini, S., Marchetti, A., Sighinolfi, S., Totaro, S., 2011. Evolution of 5-(hydroxymethyl)furfural and furfural in the production chain of the aged vinegar Aceto Balsamico Tradizionale di Modena. Food Chemistry 124, 822-832.
Consonni, R., Cagliani, L.R., Rinaldini, S., Incerti, A., 2008. Analytical method for authentication of Traditional Balsamic Vinegar of Modena. Talanta 75, 765-769.

Corradini, F., Franchini, G., Marchetti, A., Preti, C., 1996. Determination of alkali and alkaline earth metals in Aceto Balsamico Tradizionale di Modena by flame atomic absorption spectroscopy. Journal of AOAC International 79, 1167-1173.

Gazzetta Ufficiale della Repubblica Italiana 1987 No 44 del 23/02/1987. D.M: 9/02/ 1987.

Glatt, H., Sommer, Y., 2006. 15 - Health risks of 5-hydroxymethylfurfural (HMF) and related compounds. In: Skog, K., Alexander, J. (Eds.), Woodhead Publishing Series in Food Science, Technology and Nutrition. Acrylamide and Other Hazardous Compounds in Heat-Treated Foods. Woodhead Publishing, pp. 328-357. https://doi. org/10.1533/9781845692018.2.328. ISBN 9781845690113.

Gomez, M.D.M.C., Brandt, R., Jakubowski, N., Andrersson, J.T., 2004. Changes of the metal composition in German white wines through the winemaking process. A study of 63 elements by inductively coupled plasma -mass spectrometry. Journal of Agricultural and Food Chemistry 52, 2953-2961.

Kowalski, S., Duda-Chodak, A., Lukasiewicz, M., Ziec, G., 2013. 5-Hydroxymethyl-2furfural (HMF) - Heat-induced formation, occurrence in food and biotransformation - a Review. Polish. Journal of Food and Nutrition Sciences 63 (4), 207-225.

Kumari, J.D., 2012. Health benefits of polyphenols and prevention of diseases in humans. International Journal of Pharmaceutical Research and Bio-Science 1 (6), 166-189.

Lalou, S., Hatzidimitriou, E., Papadopoulou, M., Kontogianni, V.G., Tsiafoulis, C.G., Gerothanassis, I.P., Tsimidou, M.Z., 2015. Beyond traditional balsamic vinegar: Compositional and sensorial characteristics of industrial balsamic vinegars and regulatory requirements. Journal of Food Composition and Analysis 43, 175-184.

Lemmetti, F., Giudici, P., 2011. Simple chemical and physycal parameters to identify aged balsamic vinegars. Industrie delle bevande 40, 12-23.

Manzini, S., Durante, C., Baschieri, C., Cocchi, M., Sighinolfi, S., Totaro, S., Marchetti, A., 2011. Optimization of a dynamic headspace-thermal desorption-gas chromatography/mass spectrometry procedure for the determination of furfurals in vinegars. Talanta 85, 863-869.

Masino, F., Chinnici, F., Bendini, A., Montevecchi, G., Antonelli, A., 2008. A study on relationships among chemical, physical, and qualitative assessment in traditional balsamic vinegar. Food chemistry 106, 90-95.

Miller, J.N., Miller, J.C., 2010. Statistics and chemometrics for analytical chemistry. Pearson Education Limited, Harlow, England. ISBN: 978-0-273-73042-2.

OIV, 2017. International code of oenological practices 2017. issue 1, ISBN 979-1091799-73-7 http://www.oiv.int/public/medias/5119/code-2017-en.pdf; Accessed 13 March 2020.

OIV, 2018. Collective Expertise Document. Manganese in vitivinicultural products: origin, influence and toxicity, 1st Edition. OIV publications. November 2018, ISBN 979-10-91799-95-9. http://www.oiv.org/public/medias/6365/manganese-in-viti vinicultural-products-origin-influence-toxi.pdf; Accessed 13 March 2020.

OIV, 2019. Compendium of international methods of wine and must analysis. ISBN 9782-85038-003-7, Edition 2019. OIV Publications. http://www.oiv.int/en/technicalstandards-and-documents/methods-of-analysis.

Regulation (EC) No 583, 2009. Commission Regulation (EC) No 583/2009 of 3 July 2009 entering a name in the register of protected designations of origin and protected geographical indications [Aceto Balsamico di Modena (PGI)]. Accessed 13 March 2020. https://eur-lex.europa.eu/LexUriServ/LexUriServ.do?uri=OJ:L:2009:175:000 7:0011:EN:PDF.

Regulation (EU) No 1151, 2012. Regulation (EU) No 1151/2012 of the European Parliament and of the Council of 21 November 2012 on quality schemes for agricultural products and foodstuffs. Accessed 13 March 2020. https://eur-lex.eur opa.eu/legal-content/EN/TXT/PDF/?uri=CELEX:32012R1151\&from=en.

Saha, D., Bhattacharya, S., 2010. Hydrocolloids as thickening and gelling agents in food: a critical review. Journal of Food Science and Technology 47, 587-597.

Salvatore, E., Cocchi, M., Marchetti, A., Marini, F., De Juan, A., 2013. Determination of phenolic compounds and authentication of PDO Lambrusco wines by HPLC-DAD and chemometrics techniques. Analytica Chimica Acta 761, 34-45.

Slunjski, S., Coga, L., Herak Custic, M., Petek, M., Spoljar, A., 2012. Phosphorus, manganese and iron ratios in grapevine (Vitis Vinifera L.) leaves on acid and calcareous soils. Acta Horticulturae 938, 299-306.

Tharanathan, R.N., 2005. Starch-value addition by modification. Critical Reviews in Food Science and Nutrition 45 (5), 371-384.

Van Leeuw, R., Kevers, C., Pincemail, J., Defraigne, J.O., Dommes, J., 2014. Antioxidant capacity and phenolic composition of red wines from various grape varieties: specificity of Pinot Noir. Journal of Food Composition and Analysis 36, 40-50.

Wise, B.M., Gallagher, N.B., 1996. The process chemometrics approach to process monitoring and fault detection. Journal of Process Control 6, 329-348. 